\title{
General Theory of Innovation
}

\author{
An Overview
}

\author{
Greg Yezersky \\ Institute of Professional Innovators (IPI); 35987 Chater Crest Road, \\ Farmington Hills MI 48335 USA; Website: www.ipinetwork.com; \\ Email:gyezersky@ipinetwork.com
}

\begin{abstract}
The odds for success of a future CAI system (as well as the present CAI movement) are completely dependent on the quality of an underlying theory of innovation and the effectiveness of its tools, processes and models. This paper establishes a set of requirements for such a theory, evaluates existing approaches, methodologies and theories (including TRIZ), and presents an overview of the General Theory of Innovation (GTI) that, in the author's opinion, satisfies most of the established criteria. The overview includes the theoretical foundation of GTI, a list of available applications, a list of future tasks, and other pertinent information.
\end{abstract}

Key words: General Theory of Innovation; evolution; natural laws; value; market.

\section{Introduction}

The effectiveness of any computer-based process largely depends on the quality of models that are used for the design of a respective software package. The models quality, in turn, is absolutely predetermined by a degree of sophistication of our understanding of the piece of reality that we try to computerize. The field of innovation and the recently emerged attempts to computerize innovation-related activities (by the global CAI community) are no exception from the above rule. Acceptance of this position leads us to the need to objectively evaluate existing innovation theories, methodologies and techniques, identify issues (if any) that need to be addressed, and solve them. Objective evaluation, in turn, requires defining innovation and establishing a set of judgment criteria.

Please use the following format when citing this chapter:

Yezersky, G., 2007, in IFIP International Federation for Information Processing, Volume 250, Trends in Computer Aided Innovation, ed. I eón-Rovira, N., (Boston: Springer), pp. 45-55. 


\subsection{Defining innovation}

First of all, we have to recognize that there are many different definitions [1] of what innovation is. Also, the global community, including our colleagues, believes that there are many different kinds of innovation. J. Schumpeter [2], for example, distinguished between five different types of innovation: new products, new methods of production, new sources of supply, the exploration of new market, and new ways to organize business. Any theory and any definition of innovation need either to embrace this complexity or find a plausible way to simplify the situation.

The goal of simplification can be achieved because all these objects of innovation (product, process, service, as well as various entities from an organization to a country) are systems. If it is possible to create a theory of innovation for systems, in general, there would be no significant difference between all these types of innovation that are often mentioned in books; they would be different applications of the same theory. Another opportunity to find a common denominator comes from the fact that each innovation (regardless of whether it is a product, process, method of marketing, business method, market, etc.) is just a visible result of a respective process (Fig. 1) that is hidden and thus is not mentioned. The point is that it is the process with its focus on a change that determines the result. It is also worth noticing that the content of an innovation, for which it is judged by the market, is defined by the end of the conceptual design stage. As a result, the author defines innovation as follows.

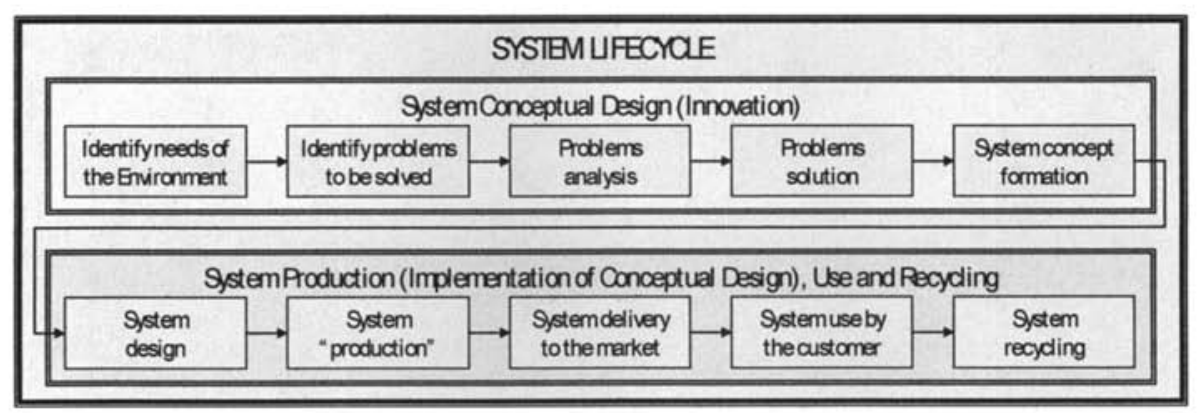

Fig. 1. The Lifecycle of a System 


\section{Definition 1.}

Innovation is a process of value creation, which consists in changing the composition of a set of variables describing a system.

\section{Definition 2.}

Innovation is an outcome out of the process that fits the definition 1.

While the second definition enables alignment with a "typical" understanding of what innovation is, the first (the primary!) definition provides most of the benefits.

- First, the definition breaks down the process of innovation into a rigid set of stages, each having its own unique goal, input and output. Thus, the further work can (and should) go in the direction of defining them, identifying the most effective tools, processes and best practices for each of the stages.

- Acceptance of the innovation as a process clearly points at the need to control each separate stage of this process in order to avoid inconsistency (variability) of results, as it is prescribed by the operation management theory and various quality methodologies.

- The corporate inability to control the process of innovation explains the phenomenon of inevitable growth deceleration, stagnation, loss of market share and eventual fall of the market leaders, which was confirmed by professors Kim and Mauborgne [3]. Since today organization don't know how to control the stage of innovation, the results of competition are random, and sooner or later the sheer force of probability determines the fall of present leaders (consider recent examples of Dell and GM).

\subsection{A set of requirements for evaluating a theory of innovation}

One of the benefits of defining innovation as a process is the possibility to define a set of requirements that any theory of innovation must satisfy. Here they are.

1. A theory must have the capability to address identified issues; analyze and solve existing problems;

2. A theory must have predictive capabilities and identify future needs (future problems) of a respective system's "Environment";

3. A theory must provide objective criteria for judging novel concepts; especially, the theory MUST provide means to evaluate the upcoming innovations potential for their future success or failure in the marketplace;

4. A theory must be objective; maximally independent from its user;

5. A theory must be universal; work for a system of any nature.

\subsection{Evaluating existing theories, methodologies and techniques}

Consideration of multiple theories [4-13], both past and contemporary, shows that all of them fail to satisfy the totality of the established requirements. Even TRIZ $[14,15]$, which is the most advanced theory, also does not meet the set criteria.

1. TRIZ, by being based on technology, is not a universal theory, which makes it inapplicable to those industries and firms that are not technology-based (e.g. banking, retail, etc.) without adapting its tools first. 
2. Even technology-based companies have innovation needs for activities that are not technology-based; for instance, HR, P\&S, strategy, etc.

3. Finally, while being able to improve products and processes, TRIZ cannot answer the most important question of all; namely, what are the odds of market success that a new concept has? The reason for this inability is again in the foundation of TRIZ that focuses on technical systems while the market that ultimately determines future success or failure of an innovation is NOT a technical system.

This situation naturally creates three distinct possibilities for creating an innovation theory that would satisfy all (or the majority) of the above established criteria.

1. Further evolve TRIZ as the theory that presently meets most of the requirements trying to expand its boundaries beyond the present limits.

2. Combine TRIZ with other existing theories, methodologies and techniques (such as marketing; QFD, Axiomatic Design, AHP, etc.) to produce desired results.

3. Create a new theory from scratch so that it would overcome shortcomings of its predecessors and satisfy all or most of the requirements.

\section{General Theory of Innovation (GTI)}

Guided by the above requirements, in 1987 the author of this paper deliberately chose the third option, which ultimately resulted in the creation of the General Theory of Innovation (GTI). Right from the start, three crucial choices were made. Just as TRIZ, the process of creating GTI was based on the historical analysis of evolutionary processes of systems. Contrary to TRIZ, the systems were deliberately chosen of different nature. Last but not least, the focus of the investigation was not on the systems themselves but on the relationships they had with their respective Environments. This means that not only solutions were analyzed, but also the problems that caused the need for these solutions as well as the conditions that made these solutions successful. Here are a few examples of the systems that were investigated.

- Sound storage medium has evolved from Edison's phonograph, to wax cylinders, to discs with lateral grooves, to double-sided discs, to reel-to-reel magnetic tapes, to 4- and 8-track tape cartridges, to compact cassettes, to CD, to DVD, to MP3.[16]

- The use of currency evolved from the barter of goods (cattle, grain, etc.), to silver ingots guaranteed by Cappadocian rulers $(2200 \mathrm{BC})$, to the first crude coins made from naturally occurring amalgam of gold and silver $(640 \mathrm{BC})$, to Chinese paper money (800 AD), to bank-backed notes $(1633-1660)$, to the first credit card (1950s), to electronic money.[17]

- Message delivery evolved from sending a messenger on foot, to a messenger on horseback, to the creation of regular mail service, to mail 
service supported by cars, trains and planes, to fax, to the next day service, to e-mail.

Despite being very different, all three examples have a number of things in common.

- Any product or service (process) is a system.

This means that each and every product or service represents the union of parts or procedures connected to each other in order to deliver value to the customers. No individual element of a system can deliver the same value on its own.

- Systems (products, services, industries) evolve.

Systems evolve over time to adapt changes in customers' needs and desires.

- Systems evolve in the predominant direction.

The course of a system's evolution coincides with the delivery of everincreasing performance while requiring less resources for providing that performance

The predominant direction of evolution can be expressed as the ratio of the sum of the functions of a system (an embodiment of performance) to the sum of connections the system needs to establish for obtaining the required resources for achieving the functionality. While functioning is easily understood, let's discuss connections in greater details. The first connection to be considered is the "customers expenditures" list (effort needed for use, time involvement, cost of ownership, space for storage, etc.), followed by requirements such as materials, energy, number of manufacturing processes and suppliers, production time, as well as sub-categories and consequences such as scrap, wastes, pollution, etc. Through the relationship between function and connection, this ratio, entitled the Coefficient of Freedom (any function empowers a system and makes it freer while any connection increases its dependency and decrease freedom), embodies the business world concept of value. The greater the Coefficient, the greater the value delivered by a product or a service.

$$
C_{\text {Freedom }}=\frac{\sum \text { Functions }}{\Sigma \text { Connections }}
$$

Historical analyses of the evolutionary process for various systems (those above, as well as bicycles, glass making, baking equipment, welding, shopping, banking, car, movie renting, publishing, the computer mouse, the car door hinge, safety airbags, etc.) clearly show the validity of the Coefficient of Freedom. It is universal, whether it is applied to products, processes, services, or various entities such as organizations (both for profit and not-for-profit), industries, markets, regions, etc. Moreover, these analyses lead firmly to the conclusion that systems do not evolve randomly; the evolutionary cycle of all systems, regardless of their specific nature, is governed by the same set of natural laws that are completely independent of human will and desire, which is the major postulate of the General Theory of Innovation (GTI), first defined in 1988. The natural law governing the process of 
evolution (growth, expansion) of various systems states that "the direction of a system's evolution coincides with a continuously increasing degree of freedom of this system's Environment" and is thus entitled the Law of an Increasing Degree of Freedom.

\section{Major Implications / Corollaries}

Acceptance of the GTI foundation, which is existence of the Natural Laws governing the process of evolution, automatically leads to the following benefits and gains that are direct corollaries (natural consequences) of the accepted position.

\subsection{The nature of a challenge (problem, failure)}

The nature of any challenge/problem/failure experienced by a system is in a deviation from the direction prescribed by the Natural laws of evolution. Consider an analogy of disobeying the natural laws of traffic on a freeway (driving against the traffic, changing lanes continually, driving with a speed that significantly differs from the one of the flow, etc.), which always elevates the risk and creates problems. Being able to efficiently identify the origins of problems, which are always a result of our choices, greatly improves our abilities to effectively address them by going to the root cause and restoring a "lawful" behavior.

\subsection{The nature of success}

On another hand, the nature of success is in the obeying the "LAWS". There is no exception from the rule. Just as we must follow the laws of physical science when designing products or services if we expect these products or services to work well, we must also follow the laws of evolution if we expect business success. Today's executives, whether they know it or not, follow these laws when they succeed. However, they do so intuitively but not consistently or methodically, thus producing very mixed results. GTI articulates evolutionary laws and introduces a set of tools for working consciously and strategically within the laws.

\subsection{The capability to forecast the future of evolution}

Knowledge of a system location on the evolutionary curve combined with knowledge of the evolutionary Laws allows any organization to forecast the system (product, process, service, etc.) future with a great degree of precision. 


\subsection{The capability to objectively judge upcoming innovations}

Existence of natural Laws of the evolutionary cycle has enabled creation of the objective criteria for evaluating proposed innovations, the importance of such criteria being self-evident. At the time of working on a direct-current motor, Thomas Edison, completely dismissed the efforts by George Westinghouse stating that alternating current was nonsense, which had no future. Every innovation improves a system, moving it along the evolutionary curve. Whether this move complies with the laws (or deviates from the laws) constitutes a criterion for evaluating the innovation.

\subsection{The capability to control the process of innovation}

With above capabilities, one can control the entire process of innovation (as defined above) thereby greatly reducing risk and variability of results, increasing manageability of the process and ROI of R\&D. Finally, while understanding that GTI (just as any other scientific theory) can be endlessly perfected, it, in principle, meets the criteria set at the beginning of this paper.

\section{Available Applications and Tools}

After 20 years, the following applications and tools have been developed based on the knowledge of the natural laws of evolutionary cycle.

\subsection{Analysis and solution of complex systems-related problems}

As we discussed previously, the essence of any problem is the fundamental conflict between the choices we made while pursuing our goals and the Natural Laws of evolution. The process essence is in identifying these choices that led to the conflict and correcting them. To accomplish these goals, the following tools were created up-to-date: RelEvent ${ }^{\mathrm{TM}}$ Diagram; Problem/Solution Templates $^{\mathrm{TM}}$; the Algorithm for Conflict Elimination (ACE); Generic strategies for conflict elimination; and so on.

\subsection{Carrying out complex projects}

When addressing a system-related problem, it is assumed that the nature of dissatisfaction is associated with a very specific aspect of the system performance: noise, strength, etc. Complex projects, as GTI defines them, relate to such important for every organization activities as cost reduction, quality, reliability, performance and productivity improvement as well as failure prevention. The reason for being called complex is that any of the above activities can be reduced to identification of those multiple (hence complex) problems, presence of which causes emergence of 
high cost (or low quality, reliability, etc.), and subsequent solution of the identified problems. All the tools, techniques and principles, which were used for analysis and solution of a single or stand-alone problem, will be also effective and valid for efficient achievement of the goals of a complex project.

\subsection{Forecasting the future of the evolution of a system}

Knowledge of a system location on the evolutionary curve combined with knowledge of the evolutionary Laws allows any organization to forecast the system (product or service) future with great degree of precision. The entire procedure of forecasting the future of a system consists of two major stages. First, by using the Laws future problems, which will cross the path of your system, are identified, and then they are solved by using the problem solving tools previously discussed.

\subsection{Innovation assessment and tools for decision-making}

Existence of natural Laws of the evolutionary cycle has enabled creation of the objective criteria for evaluating proposed innovations, the importance of such criteria being self-evident. Compliance with the evolutionary laws (or deviation from the laws) constitutes the foundation for evaluating an innovation.

\subsection{Patent circumvention or patent protection against circumvention}

At the heart of any patent, there is a solution for a problem. Patent circumvention then is finding an alternative solution for the same problem; or finding and solving an alternative problem for the same goal; or finding an alternative goal, followed by identification of a problem needed to be solved to reach the goal and subsequent solution of this problem, for which tools are available. The patent protection against circumvention is the opposite procedure and is carried out in the similar fashion.

\subsection{Strategic management (business applications)}

GTI states that innovation in the area of strategic management (identification of a change required for repositioning an organization with the purpose of obtaining competitive advantage) is immeasurably more important than innovation in any other area of corporate activities such as product or process innovation. The reasoning behind this very firm position is simple: the history of business definitely shows that companies with inferior products but superior strategies beat their technically superior competitors. Examples abound: Microsoft vs. Apple; Dell vs. IBM and Compaq; Big 3 vs. Tucker Corporation (founded by Preston Tucker).

Knowledge of the evolutionary laws is applicable not only to such systems as technology-based products, services, processes but also to the organizations (both 
for-profit and not-for-profit), industries and markets, which are also the systems. Moreover, application of GTI to the strategic management enabled creation of specialized tools such as Generic Growth Strategies; Value Matrix; Value Growth Templates and other. If an organization can precisely forecast the future of its own products and processes as well as foresee where the market will go, this company can use this knowledge at any moment for creating new powerful strategies, finding new markets for products and services, finding new sources of revenue, generating and controlling growth. This company will have a substantial advantage comparing to its uninformed rivals, which is the solid foundation for continuous advantage and success.

\subsection{Strategic Innovation}

Not all innovations are born equal! Out of the minority that are financially successful, a very few are capable of moving the markets and increase the market share for their creators. The deliberate (on-demand) creation of these innovations is the essence of this application that involves analysis of such systems as the market, a respective company with the focus on its strategy and products (services) that the company delivers to the marketplace. The GTI-based process of creation of strategic innovations is shown below (Fig. 2). The process of Strategic Innovation was created in cooperation with Dr. Paolo Mutti (Milan, Italy).

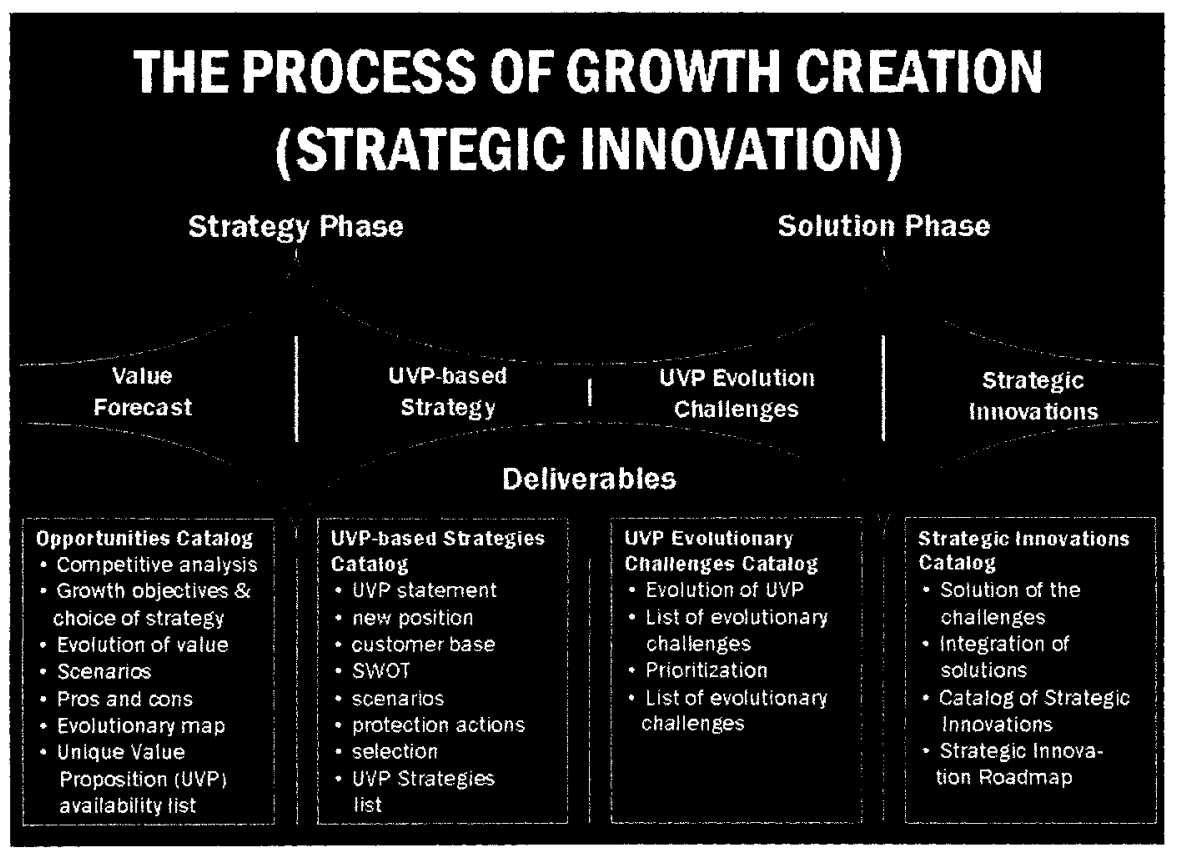

Fig. 2. The Process of Creating Strategic Innovations

(in cooperation with Dr. Paolo Mutti, Italy) 


\section{GTI: Looking into the Future}

Although GTI has been developed for about 20 years and can answer many questions that were considered unanswerable even yesterday, it can and should be evolved further because there is no such a thing as a perfect theory; further improvement is always possible, and evolution is unstoppable. The author also recognizes that the progress can be achieved easier if pursued by a team of colleagues; so everyone interested in the subject of GTI is invited to contribute. Accomplishment of the following goals is considered critically important by the author.

1. Develop and continuously evolve the General Theory of Innovation (GTI) and its various applications.

2. Disseminate GTI throughout the society starting with primary education.

3. Seamlessly align GTI with other sciences and theories, including TRIZ Collaborate with societies and organizations with common interests.

4. Work diligently toward the situation where society will recognize Innovation as a distinct profession.

5. Standardize materials for and methods of preparing specialists pursuing the goal of becoming proficient in GTI and a variety of its applications.

6. Develop and introduce a process of certifying Innovators recognized by the global business and academic communities.

\section{Acknowledgements}

The author would like to acknowledge contribution of the following individuals to the creation and development of the General Theory of Innovation; without them the results that have been achieved would be absolutely impossible.

1. Genrich S. Altshuller, the late father of TRIZ, who encouraged the original research and provided a number of priceless suggestions;

2. Alexander A. Malinovsky (Bogdanov), the late father of Tectology (1920) whose work [18] prophetically preceded many of the results by Altshuller, Bertalanffy [19], and Wiener [20];

3. Dr. Lev L. Velikovich (Belarus), a close friend and mentor, who was the first to recognize the importance of GTI and encouraged the research;

4. Dr. John Terninko, a close friend and an intellectual sparring partner, who continuously challenged every aspect of GTI, including axioms and assumptions, thereby making GTI stronger;

5. Dr. Gaetano Cascini (Italy), a close friend and colleague; whose advice and opinion is always relevant and thoughtful;

6. Dr. Noel Leon (Mexico), who has invented the term of the General Theory of Innovation and generously presented it to the author;

7. Greg Frenklach (Israel) with whom the original research was conducted;

8. My countless TRIZ colleagues, whose works contributed to my upbringing and understanding of the world; 
9. Last but not least; my family (wife Larisa Yezersky, our sons Geoffrey, Andrew and Alexander; my late father Abraham Yezersky, and my mother Fira Yezersky), whose unconditional love and unwavering support allowed me pursuing the goal of creating GTI.

\section{References}

1. Wikipedia, URL: http://en.wikipedia.org/wiki/Innovation.

2. Schumpeter, J. (1934), The Theory of Economic Development (Harvard University Press, Cambridge, Massachusetts).

3. W. Chan Kim, Renee Mauborgne, Blue Ocean Strategy, (HBS Press, Boston, 2005)

4. Alex F. Osborn, Applied Imagination, (Creative Education Foundation, 1993)

5. Fritz Zwicky, Discovery, Invention, Research through the Morphological Approach, (MacMillan Publishing Company, Toronto, 1969)

6. William J. J. Gordon, Synectics, (MacMillan Publishing Company, Toronto, 1971)

7. Edward De Bono, Lateral Thinking, (Harper Paperbacks, New York, 1973)

8. James M. Higgins, 101 Creative Problem Solving Techniques, (New Management Publishing, 1994)

9. Michael MIchalko, Thinkertoys, (Ten Speed Press, Berkley, 1991)

10. Clayton M. Christensen, The Innovator's Dilemma, (HarperBusiness, New York, 2000)

11. Clayton M. Christensen, Michael E. Raynor, The Innovator's Solution, (HBS Press, Boston, 2003)

12. Clayton M. Christensen, Erik A. Roth, Scott D. Anthony, Seeing What's Next, (HBS Press, Boston, 2004)

13. Constantinos C. Markides, Paul A. Geroski, Fast Second, (Jossey-Bass, San Francisco, 2005

14. G. S. Altshuller, Creativity As An Exact Science, (Gordon and Breach, New York, 1988)

15. Genrich Altshuller, The Innovation Algorithm, (Technical Innovation Center, Worcester, 1999)

16. Steve Schoenherr, Recording Technology History, notes; Website URL: http://history.sandiego.edu/GEN/recording/notes.html

17. Glyn Davies, A history of money, (University of Wales Press, 1996) and also at Website URL: http://www.ex.ac.uk/ RDavies/arian/llyfr.html

18. Alexander A. Bogdanov (Malinovsky) Tektologia, (Economika Publishing House, Moscow, 1989, in Russian)

19. Ludwig von Bertalanffy, General System Theory, (George Braziler, New York, 1968)

20. Norbert Wiener, Cybernetics, (The Technology Press, New York, 1948) 